\title{
Produtos agropecuários: para quem exportar?
}

\author{
Daniel da Mata ${ }^{1}$ \\ Rogério Edivaldo Freitas ${ }^{2}$
}

Resumo: Este trabalho procurou discutir fatores de atração das exportações agropecuárias brasileiras. Para tal implementou-se um modelo gravitacional acrescido de procedimentos econométricos de efeitos fixos e aleatórios, além da abordagem por Mínimos Quadrados Ordinários (MQO). As principais variáveis identificadas como determinantes dessas exportações foram a distância para os mercados de destino, o PIB dos parceiros comerciais e a localização geográfica do país importador. Ademais, verificaram-se efeitos puzzles para a taxa de câmbio, o perfil agroexportador do país importador e a participação do setor agrícola na economia de destino. Por fim, o trabalho realça uma diferenciação das variáveis relevantes em função de características específicas dos parceiros comerciais brasileiros.

Palavras-Chave: exportações, modelo gravitacional, setor agropecuário.

Abstract: The paper discussed the main factors that explain the Brazilian agricultural exports. In order to achieve this goal, the paper applied a gravity model that includes fixed and random effects estimations, besides the Ordinary Least Squares (OLS) approach. Distance, trade partners' GDP, and geographical localization were the significant

\footnotetext{
${ }^{1}$ Economista, e Técnico de Planejamento e Pesquisa do IPEA.

${ }^{2}$ Economista, e Técnico de Planejamento e Pesquisa do IPEA.
} 
variables. Moreover, puzzle effects are associated to exchange rate, partners' agricultural exports profile and the partners' agricultural share in GDP. Finally, this study highlights the potential change of the relevant variables because of specific characteristics of each commercial Brazilian partner.

Key Words: exports, gravity model, agricultural sector.

JEL Classification: Q17, F13

\section{Introdução}

Atualmente, as exportações de produtos agropecuários representam em torno de $28 \%$ das divisas de exportações do país. Ademais, o setor responde por parcela significativa do superavit comercial brasileiro, constituindo-se em elemento chave para o equilíbrio das contas externas.

Ao mesmo tempo, as cadeias de produtos agropecuários respondem por parcela importante do Produto Interno Bruto (PIB) (MAIA ET AL., 2005). De acordo com Guilhoto, Silveira e Azzoni (2004), em 2003, $30,6 \%$ da renda total da economia brasileira foram derivados do agronegócio, considerando-se nesta categoria as empresas que fornecem insumos às unidades agropecuárias, as unidades agropecuárias em si, as empresas processadoras e as empresas distribuidoras.

Em particular na região Nordeste, a agricultura corresponde a 34,5\% das exportações, a 9,8\% do PIB local, e a $4 \%$ da força de trabalho ali ocupada. Nestes termos, os impactos regionais de estímulos ao setor podem ser ainda mais significativos.

Esse quadro é o pano de fundo que destaca a importância em se conhecer de forma clara os fatores que afetam as vendas para o exterior dos produtos agropecuários brasileiros.

Em itens importantes das exportações agropecuárias, o Brasil exerce papel de um dos principais ofertantes no mercado mundial, a saber: açúcar (ao lado de União Européia ${ }^{3}$ e Índia), soja e derivados (ao lado de Argentina e Estados Unidos), suco de laranja (ao lado dos Estados Unidos), e café (ao lado da Colômbia). Em alguma medida, muitos

\footnotetext{
${ }^{3}$ Inclui os valores viabilizados através de subsídios às exportações.
} 
desses setores podem estar se tornando mais concentrados na sua etapa de processamento, com é o caso da soja, do suco de laranja e do açúcar, devido à presença de grandes traders, por exemplo, o que aponta para a possibilidade de controles de oferta ao arbítrio dos agentes privados situados naqueles pontos da cadeia produtiva, com impactos necessários sobre a produção inicial e comercialização.

Em termos de destinos, há um movimento de expansão e diversificação das exportações para novos mercados, embora seja ainda importante a participação de países como os Estados Unidos e os da Europa (Alemanha, Reino Unido, Países Baixos, Rússia, Itália etc.). Nos últimos anos, tem crescido o comércio internacional dos principais grupos de produtos agropecuários brasileiros com países da Ásia e do Oriente Médio, como a China, Índia, e Arábia Saudita, ao mesmo tempo em que existe uma certa concentração da pauta agroexportadora em determinados grupos de produtos.

Os anos da década de 1990, em particular, representaram um momento de profundas transformações da economia brasileira. Nesse novo cenário, o setor agropecuário tem se destacado por sua contribuição ao crescimento da economia local, mesmo sob grandes entraves macroeconômicos como, por exemplo, a política de juros altos.

No seu desempenho externo, diversos fatores afetam a capacidade de exportação dos produtos agropecuários brasileiros. Estes fatores contemplam as vantagens comparativas locais, a solução de restrições infra-estruturais domésticas, as restrições comerciais externas e variáveis macroeconômicas.

As vantagens comparativas do País exercem um papel primordial. Essas vantagens comparativas já existiam e foram aproveitadas ou desenvolvidas a partir de decisões de políticas públicas. Vários resultados decorreram de tais decisões - como, por exemplo, o desenvolvimento de novas técnicas de produção e a geração de novas variedades vegetais e animais - graças à construção de uma rede de universidades e institutos de pesquisa ligada à produção agropecuária. Esse processo permitiu não apenas solucionar gargalos do abastecimento alimentar doméstico bem como gerar superavits de produção que transformaram o agronegócio brasileiro num dos mais dinâmicos setores da economia brasileira.

$\mathrm{O}$ segundo fator refere-se à infra-estrutura logística. O processo 
exportador requer uma infra-estrutura logística doméstica e uma disponibilidade energética tais que a atividade exportadora seja de fato rentável para o empresário local.

As regras do comércio internacional representam um terceiro filtro para que os produtos brasileiros atinjam mercados externos com a geração de divisas para o país. Segundo Anderson, Martin, e Van der Mensbrugghe (2005), o Brasil obteria incrementos comerciais expressivos (US\$ 38 bilhões até 2015) caso as barreiras comerciais fossem removidas. Atualmente, o Brasil participa de exercícios de integração comercial com resultados que serão significativos para os diferentes setores produtivos. A própria participação brasileira no chamado Grupo de Cairns bem como a recente atuação ao lado de países como a Índia sob a roupagem do G20 na Rodada de Doha mostram a centralidade econômica e política do tema.

No caso da Área de Livre Comércio das Américas (ALCA), a polarização de propostas, a amplitude de temas tratados e a pouca disposição de estabelecer regras claras e abrangentes têm direcionado o diálogo para o foco dos problemas e exceções, em lugar de apontar soluções para um comércio internacional mais intenso. Tais características têm enfraquecido os resultados e a profundidade desse processo negociador.

Já as reuniões do fórum biregional União Européia (UE)-Mercosul ganham relevância à proporção em que se torna claro que uma das dificuldades do histórico das relações entre o Brasil e a Europa unificada sempre esteve no entrave quanto ao ingresso de produtos agropecuários nas economias capitalistas do velho continente. Todavia, as negociações bilaterais não têm sido efetivas em solucionar os problemas de acesso das commodities agropecuárias e alimentos processados brasileiros ao mercado consumidor da UE.

Além disso, é válido frisar a existência de mercados potenciais representada pelos países de mesmo nível de desenvolvimento que o Brasil, como Índia, China e África do Sul, sem citar o restante dos países em desenvolvimento que compreende parte dos países asiáticos, africanos e latino-americanos.

Sob este aspecto, o crescimento dos acordos preferenciais e de outras formas de integração comercial e econômica dá-se concomitantemente ao processo de fragmentação política verificado desde a segunda metade do 
século XX. De acordo com Braun, Hausmann e Pritchett (2002), cerca de 125 novos países foram criados entre 1943 e 1994, mais do que o dobro do número de países existentes ao final da Segunda Guerra Mundial.

Nesse contexto, a própria existência de acordos preferenciais ao estilo África, Caribe e Pacífico (ACP), Países de Menor Desenvolvimento Relativo (PMDR), ou Sistema Geral de Preferências (SGP) sinaliza para o reconhecimento de diferenciações por origem do produto aos olhos do próprio país comprador ${ }^{4}$.

Como quarto condicionante, mas não menos importante, citam-se os elementos da macroeconomia local, em particular a taxa de câmbio e o ambiente tributário. Em dada medida, esses elementos podem limitar ou expandir substancialmente a rentabilidade da atividade exportadora. Segundo Homem de Melo (2005) parte do crescimento das exportações brasileiras pós-1999 decorreu dos incentivos à atividade exportadora no contexto de desvalorização da moeda local. Não obstante, parte do incremento nas vendas externas está associada a esforços comerciais empreendidos por várias instâncias governamentais. São exemplos nesse sentido, a Lei Kandir que desonerou parte das exportações do país no começo da década de 1990, e a ênfase em capacitação e know-how dos exportadores brasileiros.

Isto posto, o presente trabalho tem por objetivo estudar os determinantes das exportações agropecuárias brasileiras, de modo a identificar características relevantes dos parceiros comerciais do Brasil. Outrossim, o trabalho visa averiguar o impacto do crescimento doméstico sobre as exportações de produtos agropecuários do Brasil e estudar se países que têm nas exportações agropecuárias uma parcela significativa da pauta exportadora total deixam de importar produtos agropecuários brasileiros.

Além da parte introdutória, o trabalho contém mais quatro seções. A segunda seção aborda o estado das artes acerca do tema. A terceira parte apresenta os procedimentos metodológicos e os dados empregados. Por fim, as seções quatro e cinco foram reservadas aos resultados e às considerações finais, respectivamente.

${ }^{4}$ Acerca desse ponto, é conhecido o caráter discriminatório desses acordos em relação às exportações agropecuárias brasileiras, conforme discutido em Castilho (2000), MDIC (2001), Bouët (2003) e Cunha Filho (2004). 


\section{Estado da Arte: variáveis de impacto sobre as exportações agropecuárias}

Diversos trabalhos têm analisado os determinantes das exportações agropecuárias brasileiras. De regra, tais estudos focam dois aspectos: os determinantes em nível de firmas ou os em nível de países. Dada a preocupação e o escopo do presente artigo, a revisão da literatura abordará somente os trabalhos com o enfoque nos determinantes da ótica do país. Nesse contexto, há um número não desprezível de artigos que se dedicam às exportações de produtos agropecuários. Essa seção procura realizar uma revisão não-exaustiva da literatura nacional e internacional do tema.

Na literatura internacional, pelos menos dois estudos merecem escrutínio. Sevela (2002) identificou três variáveis para o estudo das exportações agropecuárias da República Tcheca, a citar, o Produto Nacional Bruto (PNB) - ou, alternativamente, o PNB per capita - dos países comprador e vendedor, a distância geográfica, e a contigüidade espacial entre as nações analisadas. Este autor versa, especialmente, acerca do efeito locacional sobre o desempenho exportador no referido país.

O impacto da integração norte-americana e do MERCOSUL sobre as exportações agropecuárias dos Estados Unidos foi estudado por Zahniser et al. (2002) tanto em nível agregado como para grupos de commodities. Esse trabalho ressalta que as exportações dos EUA para o México foram significativamente maiores que as exportações dos EUA para outros países no período de 1980-1999, tanto para agregado quanto para 14 produtos agropecuários selecionados. Por outro lado, os resultados para o Canadá foram bastante limitados e não significantes estatisticamente. $\mathrm{O}$ estudo concluiu que o estabelecimento do MERCOSUL desviou parte das exportações agrícolas dos EUA, fenômeno particularmente notável em relação às exportações norte-americanas de trigo para o Brasil, uma vez que foram substituídas pela oferta argentina.

Outros seis trabalhos, na literatura nacional, particularmente alinhados com a preocupação do presente artigo são Castilho (2001), Carvalho e De Negri (2000), Barros, Bacchi e Burnquist (2002), Maia (2003), Reis e Crespo (1998) e Fonseca e Hidalgo (2006).

Castilho (2001) estimou equações gravitacionais por setores de atividade 
econômica (dentre eles o agropecuário), incluindo, por exemplo, distância e língua comum como variáveis explicativas. Os coeficientes estimados para distância foram negativos e significativos. No caso da língua comum, detectou-se uma influência positiva sobre os fluxos comerciais bilaterais. Evidenciou-se também o caráter discriminatório das barreiras comerciais e dos acordos comerciais preferenciais, em particular nos casos de carnes e miudezas, açúcares e confeitaria e vinhos e bebidas.

O texto de Carvalho e De Negri (2000) emprega a metodologia de vetores auto-regressivos (VAR) com testes para a exogeneidade das variáveis ${ }^{5}$ e baseia-se em um modelo de substituição imperfeita de bens em equações simultâneas de comércio exterior, com foco nos grupos de produtos agropecuários importados e exportados, segundo a definição da Fundação Centro de Estudos do Comércio Exterior (FUNCEX). Concluiu-se que as exportações agropecuárias brasileiras eram influenciadas basicamente pelo nível de atividade mundial e, em menor medida, pela taxa de câmbio real. Além disso, os autores não detectaram significância no papel desempenhado pelo PIB doméstico, em termos de explicação das exportações agropecuárias.

Barros, Bacchi e Burnquist (2002) trataram a oferta de exportações agropecuárias como um excesso de oferta doméstica sobre a demanda local, empregando os procedimentos de Johansen e termo de correção de erro se as variáveis apresentassem co-integração. Os autores empregaram tal metodologia para análises pontuais no caso do frango, farelo de soja, carne bovina resfriada e congelada, carne bovina industrializada, açúcar, algodão, café, e suco de laranja, e empregaram dados de jan/92 a dez/00, salvo no caso do açúcar (jan/95-dez/00) e carne bovina industrializada (set/94-dez/00). Três foram as principais conclusões do trabalho. Em primeiro lugar, impactos do crescimento da economia brasileira sobre as exportações dos produtos analisados mostraram-se expressivos ${ }^{6}$. Como segundo ponto, ressalta-se que a

\footnotetext{
${ }^{5}$ As principais variáveis empregadas no referido modelo foram: a taxa de câmbio, o subsídio à comercialização, os preços de exportação, os preços domésticos, o produto efetivo local, o produto potencial local, e o produto externo efetivo.

${ }^{6}$ As variáveis incluídas na análise foram: quantidade exportada, preço do mercado interno do produto, taxa de câmbio efetiva, preço recebido pelas exportações, renda nacional real, variáveis binárias representando os diferentes meses do ano e variáveis binárias que representam os anos da amostra.
} 
taxa de câmbio é fator determinante das exportações do agronegócio, em especial no caso da soja (e derivados) e do açúcar. Além disso, os preços de exportação mostraram-se relevantes nos casos de açúcar, soja, e carne industrializada.

O referido artigo é bastante útil em esclarecer as nuances específicas de cada mercado e produto considerado, o que certamente contribui para uma melhor qualificação dos resultados obtidos caso a caso, vez que os mercados de suco de laranja e de algodão são intrinsecamente diferentes, por exemplo.

Por seu turno, Maia (2003) utilizou o modelo Mundell-Flemming para análise do impacto das variáveis do mercado de ativos sobre as políticas econômicas em diferentes cenários de regimes cambiais, o qual foi operacionalizado através de um modelo VAR com causalidades contemporâneas. O autor realizou um recorte de análise de modo a comparar os resultados de dois subperíodos (1980-1990 versus 19902001) sob o argumento de que o segundo período desenvolveu-se em um ambiente de economia aberta. No mencionado trabalho, os produtos componentes do grupo das exportações agrícolas foram: soja em grão, farelo de soja, óleo de soja, amêndoas de cacau, manteiga de cacau, café em grão, café solúvel, suco de laranja e açúcar.

Os resultados a se destacar seriam a redução do poder de explicação da taxa de câmbio sobre as exportações a partir de 1990 e o aumento de participação da taxa de juros sobre a variância da previsão das exportações de 1990 em diante. Adicionalmente, no segundo período, de economia aberta, os choques autônomos de cada variável do sistema foram absorvidos de forma mais rápida.

Ainda, Reis e Crespo (1998) aplicaram um modelo de equilíbrio simultâneo entre oferta e demanda com correção de mínimos quadrados de dois estágios (MQO2) para avaliação das exportações brasileiras de açúcar, assumindo concorrência imperfeita no mercado internacional do produto face à importância do Brasil como ofertante. Do lado da oferta, as variáveis utilizadas foram o preço unitário do açúcar brasileiro exportado, o preço interno de varejo do açúcar no Brasil, o consumo aparente de açúcar no Brasil, a taxa de câmbio real e o estoque inicial de açúcar no mundo. No que concerne ao lado da demanda, empregaram-se o preço unitário do açúcar brasileiro exportado, o Produto 
Interno Bruto (PIB) dos principais países importadores de açúcar brasileiro, a quantidade de açúcar exportada pela América (excluindo o Brasil e Cuba) e o preço unitário das exportações mundiais de produtos substitutos do açúcar.

Os autores utilizaram dados do período entre 1961 e 1994 e destacam-se quatro conclusões interessantes do trabalho. Em primeiro plano, a elasticidade renda calculada sugere que o açúcar é um bem superior para os países importadores. Em segundo lugar, a exportação de açúcar parece ser uma atividade mais dependente da situação do mercado interno que da conjuntura internacional. Como terceiro ponto, em muitos momentos, o efeito positivo dos preços internacionais do açúcar tem sido capaz de suplantar os efeitos negativos (sobre as exportações do produto) de um câmbio valorizado. E, por fim, grandes estoques de açúcar podem induzir os maiores produtores a elevar sua oferta de exportações - mesmo que com nova queda de preços - caso os custos de estocagem sejam superiores ao custo de exportar a preços declinantes.

Fonseca e Hidalgo (2006) analisaram o potencial efeito da ALCA sobre as exportações agrícolas brasileiras, em especial para seis produtos: café, cacau, soja, açúcar, suco de laranja e carnes. Utilizando um modelo de equilíbrio parcial para estimar os efeitos de primeira ordem da integração regional da ALCA no setor agropecuário brasileiro, chegou-se ao resultado de que, a partir de simulações entre 1999 e 2002, o efeito criação de comércio foi superior ao efeito desvio de comércio, caracterizando a competitividade dos produtos do agronegócio e os prováveis benefícios de integração comercial no referido acordo de livre comércio.

A parte referente aos resultados do presente estudo realizará um contraste dos resultados da literatura com os encontrados nos procedimentos econométricos utilizados.

\section{Procedimentos Metodológicos e Estratégia Empírica}

A metodologia empregada no presente trabalho segue uma equação gravitacional (gravity equation) tradicional, do estilo log-linear. Essa ferramenta tem sido largamente usada em trabalhos empíricos na 
área de economia internacional, tanto no agregado da pauta comercial como para subgrupos de produtos. Segundo Feenstra, Markusen e Rose (2001), a equação gravitacional ajusta-se razoavelmente bem tanto para os países da OCDE como para as nações em desenvolvimento. Alguns dos trabalhos seminais empregando essa metodologia foram Anderson (1979), Bergstrand (1985), e Bergstrand (1989).

A intuição da equação gravitacional origina-se da Física: quanto maior a renda e a população de um parceiro comercial e quanto menor a distância em relação a ele, maior o montante de comércio entre duas nações. Uma das principais razões para a difusão desse procedimento, como frisado anteriormente, é o bom ajuste que ele tem proporcionado em muitos trabalhos empíricos.

Sem embargo, essa boa aderência empírica suscitou certo debate e algumas críticas sob o argumento de que tal metodologia ainda carece de melhor embasamento teórico. Além disso, muitos analistas ressaltam questões de especificação econométrica ainda não bem resolvidas no uso do modelo gravitacional.

Em contrapartida, nas discussões teóricas do modelo gravitacional, há análises que o associam aos modelos de competição monopolística (KRUGMAN, 1980), aos modelos de dumping recíproco (FEENSTRA, MARKUSEN e ROSE, 1998), às análises de diferenciação perfeita entre produtos de diferentes origens (estrutura de Armington) em Feenstra, Markusen e Rose (2001), ou à estilização do modelo Heckscher-Ohlin (DEARDOFF, 1998). Sobre os fundamentos econômicos da equação de gravidade, referências importantes são Anderson (1979), Bergstrand (1985) e Evennet e Keller (2002).

Bergstrand (1985), por exemplo, desenvolveu uma forma gravitacional generalizada, em resposta a muitos artigos que refutavam o uso do modelo gravitacional na análise de bens de perfeita substitutibilidade no comércio internacional e sob arbitragem perfeita. A conclusão principal do trabalho é que a existência de produtos diferenciados nacionalmente (seja em termos de distância ou por conta de características específicas do país produtor) descaracteriza o quadro de arbitragem perfeita em muitos casos.

Com base em quatro regressões do tipo cross sections realizadas para os fluxos comerciais totais de 15 países da OCDE, o autor estimou 
duas versões do modelo gravitacional: a primeira referida como "padrão" e a segunda tida como forma "generalizada" por incluir variáveis explicativas características de cada país ${ }^{7}$. Para a maior parte dos coeficientes que se referiam às mesmas variáveis explicativas, os valores estimados foram similares nas duas versões do modelo. Além disso, os quatro anos analisados no mencionado estudo apresentaram resultados mais estáveis na forma generalizada, bem como maior robustez estatística. Ante tais resultados, o autor argumenta pela adoção da forma generalizada, mais robusta estatisticamente e melhor definida teoricamente.

Bergstrand (1989) apresenta embasamentos microeconômicos para o uso do modelo gravitacional e inclui, na sua análise, variáveis de dotação de fatores relacionadas ao modelo Heckscher-Ohlin. Desta feita, o autor faz análises desagregadas por grupos de produtos e demonstra que, dentre os quatro anos avaliados, em no mínimo dois períodos, os produtos alimentícios poderiam ser considerados intensivos em capital. Sobretudo, o autor afirma que dois setores similares (em países distintos) podem produzir o mesmo item com diferenciação somente na presença de mercados em concorrência monopolística. Esse argumento, numa roupagem moderna sinaliza para a identificação de nichos de mercado sob concorrência não perfeita.

Não menos importante, o trabalho citado representa um grande esforço para dar consistência ao modelo gravitacional entre as tradicionais e as novas teorias de economia internacional. Mais explicitamente, o autor usa uma função utilidade CD-CES transformada e assume, do lado da oferta, que os produtores ofertam bens levemente diferenciados, originando um mercado de competição monopolística.

Em especial acerca da especificação econométrica da equação gravitacional, trabalhos recentes ${ }^{8}$ debatem estratégias teóricas e procedimentos para melhorar a precisão e robustez dos modelos gravitacionais,

\footnotetext{
${ }^{7}$ Especificamente, as taxas de câmbio, índices de valor das exportações e de valor das importações, e os deflatores dos respectivos PIBs. Essa forma generalizada é tratada como um subsistema de equilíbrio parcial de um modelo de comércio de equilíbrio geral com produtos diferenciados nacionalmente.

${ }^{8}$ Um aprofundamento desse ponto foge ao objetivo e escopo do presente texto. O leitor interessado poderá encontrar maiores detalhes em Porojan (2000), Cheng e Wall (2004), e Santos Silva e Tenreyro (2005).
} 
as quais, muitas vezes não são operacionalizáveis por conta da natureza e volume de dados que demandam.

É válido ressaltar que vários estudos nacionais contemplam a análise do fluxo comercial com a metodologia das equações gravitacionais, como é o caso de Castilho (2001). A título de ilustração, Piani e Kume (2000) reforçam que fatores tradicionalmente identificados na literatura, como renda do país importador, renda per capita e distância entre os mercados vendedor e comprador são determinantes-chave das exportações brasileiras.

Hidalgo e Vergolino (1998) utilizaram um modelo gravitacional para estudar o impacto das barreiras nacionais (entre unidades de federação) e internacionais ao comércio. Nesse trabalho, foram incluídas variáveis como PIB doméstico e externo, distância e receita de exportações, além de variáveis dummies para captar os fluxos comerciais domésticos. Os resultados destacaram a existência de importantes barreiras políticas ao comércio.

Paz e Franco Neto (2003) estimaram o efeito de fronteira geográfica no comércio brasileiro em modelos Tobit ou pooled cross sections. No artigo, os autores destacaram a flexibilidade da equação gravitacional para incorporar a maior parte dos fenômenos empíricos observados no comércio internacional, como o grande volume de comércio entre os países industrializados, o comércio intra-indústria ou mesmo resultados de ajuste de liberalização comercial.

\section{Especificação Econométrica}

A estratégia empírica inicia-se com uma função de produção CobbDouglas na sua expressão convencional:

$$
F_{i j}=\alpha_{0} \times \prod_{k=1}^{n} X_{k}^{\alpha_{k}} \times e^{u_{i j}}
$$

Na equação (1), tem-se que:

- $\quad F_{i j}$ : fluxos comerciais da economia ${ }_{i}$ para a economia ${ }_{j}$;

- $\quad \mathrm{X}_{\mathrm{k}}$ : variáveis explicativas;

- $\quad \alpha_{0}$ : constante;

- $\quad \alpha_{\mathrm{k}}$ : parâmetros do modelo; 
- $\quad$ n: número de variáveis explicativas;

- $\quad \mathrm{u}_{\mathrm{ij}}$ : termo errático com as hipóteses do modelo clássico de regressão.

A equação acima pode ser traduzida em uma expressão log-linear, que é linear nos parâmetros, linear nos logs das variáveis $\mathrm{F}$ e $\mathrm{X}^{9}$, e pode ser estimada pelo método dos mínimos quadrados ordinários (MQO). Nesses termos, para os propósitos da presente análise, tem-se a equação (2):

$$
\ln F_{i j t}=\alpha_{0}+\sum_{i=1}^{n} \beta_{k} \ln X_{k i j t}+\varepsilon_{i j t}
$$

Em que:

- $\quad \ln \mathrm{F}_{\mathrm{ijt}}$ : $\log$ das receitas de exportação de $\mathrm{i}\left(\right.$ Brasil $\left.={ }_{\mathrm{i}}\right)$ para a economia ${ }_{j}$ no momento ${ }_{t}$;

- $\quad \ln \mathrm{X}_{\mathrm{k}}$ : matriz de logs das variáveis explicativas;

- $\alpha_{0}$ : constante;

- $\quad$ n: número de variáveis explicativas;

- $\varepsilon_{\mathrm{ijt}}$ : termo errático com as hipóteses do modelo clássico de regressão.

Neste estudo, os fluxos comerciais são as exportações agropecuárias brasileiras. Nesse caso os produtos incluídos correspondem à definição de agropecuária da Rodada do Uruguai (sistema GATT/OMC). Assim, como critério de categorização, utilizou-se o Sistema Harmonizado (SH) de Classificação de Mercadorias, de modo que os dados contemplam os capítulos do $\mathrm{SH}$, conforme a Tabela 1 .

As variáveis explanatórias aqui empregadas foram escolhidas em linha com os postulados tradicionais da equação gravitacional e/ou a partir dos trabalhos relacionados com a identificação de determinantes das exportações agropecuárias brasileiras. A lista de variáveis inclui: distância do parceiro comercial até o Brasil, Produto Interno Bruto (PIB) dos países importadores, dummy para países africanos, dummy para países do Leste Asiático e Pacífico, dummy para países da América

\footnotetext{
${ }^{9}$ Para uma discussão em pormenores ver Greene (2000).
} 
Latina, população total dos parceiros comerciais, porcentagem do setor agrícola no PIB do país importador, porcentagem das exportações agropecuárias nas exportações totais do país importador, porcentagem da população rural na população total do país importador, taxa de câmbio (paridade do poder de compra - PPP), PIB per capita do Brasil, e grupo de países componentes do G20.

O período avaliado compreende de 1996 a 2001, para o qual todas as informações estavam disponíveis. Procurou-se obter informações referentes aos anos de 2002 e posteriores. Todavia, dada a grande massa de dados ausentes para muitos países em desenvolvimento e que, não raro, possui sistemas de informações muito simples e menos cuidado comparativamente ao caso brasileiro, somente o intervalo de 1996 a 2001 apresentou informação completa para quase todos os países do mundo, conforme aqui elaborado. As fontes de dados utilizadas estão relacionadas na Tabela 2 .

Tabela 1 - Produtos definidos no Acordo Agrícola (Rodada do Uruguai).

\begin{tabular}{cc}
\hline Capítulo do SH & Itens \\
\hline 1 e 2 & Todos \\
4 a 24 & Todos (exceto 1603 a 1605) \\
29 & 2905.43 e 2905.44 \\
33 & 33.01 \\
35 & 35.01 a 35.05 \\
38 & 3809.10 e 3823.60 \\
41 & 41.01 a 41.03 \\
43 & 43.01 \\
50 & 50.01 a 50.03 \\
51 & 51.01 a 51.03 \\
52 & 52.01 a 52.03 \\
53 & 53.01 e 53.02 \\
\hline
\end{tabular}

Fonte: FTIS (2002).

Esses produtos têm representado parcela significativa das receitas de exportações e do saldo comercial brasileiro, conforme se pode observar do gráfico a seguir. 
Gráfico 1 - Proporção da agropecuária nos fluxos comerciais (US\$) brasileiros, 2004-2006.

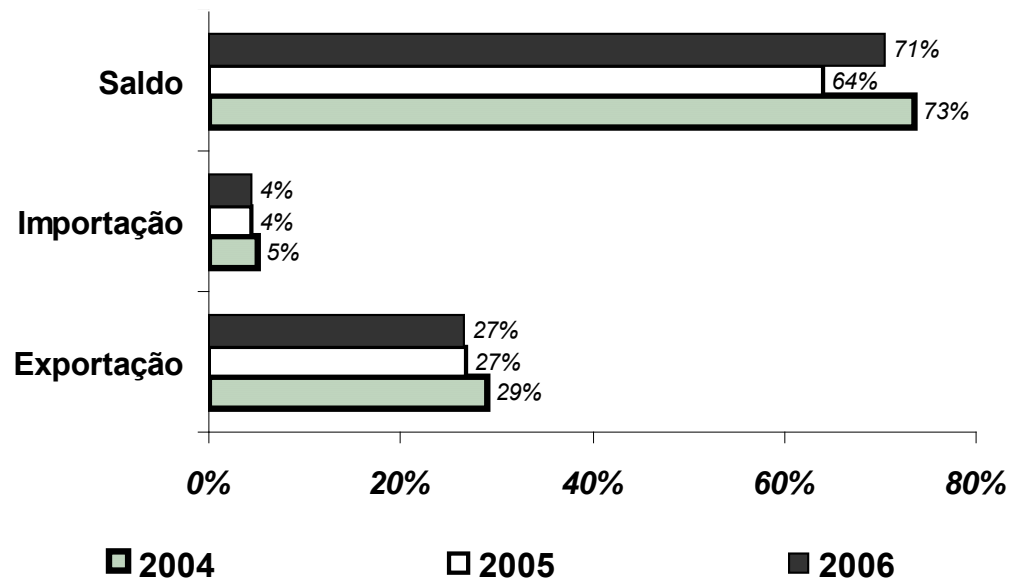

Fonte: Dados extraídos do Aliceweb (http://aliceweb.mdic.gov.br/). MDIC (2007).

Nota: Definição de produto agropecuário segundo especificado no Acordo Agrícola da Rodada do Uruguai.

A introdução dos países do $\mathrm{G} 20^{10}$ como variável dummy no processo de modelagem representa a inclusão de um argumento de economia política. O G-20 é uma coalizão de países em desenvolvimento formada durante as negociações preparatórias à reunião Ministerial de Cancún, da Organização Mundial do Comércio (OMC). Esta coalizão elaborou uma proposta liberalizante para subsídios domésticos e para subsídios a exportações, bem como para o acesso aos mercados por parte dos países desenvolvidos, em contraposição à proposta agrícola protecionista apresentada em conjunto pela UE e pelos EUA (ICONE, 2007).

A participação no grupo sinaliza que seus componentes teriam, ao menos em tese, interesses diplomáticos alinhados à estratégia brasileira nas negociações realizadas no âmbito da $\mathrm{OMC}$, o que, em termos práticos, poderia sinalizar países com estruturas de oferta de produtos agropecuários - efetiva ou potencialmente - próximas da condição brasileira.

${ }^{10}$ A composição original do G20 contempla os seguintes países: África do Sul, Argentina, Bolívia, Brasil, Chile, Filipinas, Guatemala, Indonésia, Paraguai, Tailândia, China, Cuba, Egito, Equador, Índia, México, Nigéria, Paquistão, Peru e Venezuela. 
Tabela 2 - Fontes de dados utilizadas.

\section{Variável}

Exportações agropecuárias do Brasil (US\$)

Distância até o Brasil

PIB total - valores constantes de 1995

População total

\% do setor agrícola no PIB

\% das exportações agropecuárias nas

exportações totais

\% da população rural na população total

Taxa de câmbio - paridade do poder de compra

Países componentes do G20

PIB per capita do Brasil - valores constantes de 1995

\section{Fonte}

Aliceweb - SECEX/MDIC

Departamento de Agricultura dos E.U.A.

Banco Mundial

Banco Mundial

Banco Mundial

Banco Mundial

Banco Mundial

Fundo Monetário Internacional

ICONE

Banco Mundial

Fonte: Elaboração própria.

Tabela 3 - Destino dos principais produtos agropecuários brasileiros em 2005.

\begin{tabular}{lccc}
\hline \multicolumn{1}{c}{ Produto } & Principal destino & $\mathbf{2}^{\mathbf{0}}$ principal & $\mathbf{3}^{\mathbf{0}}$ principal \\
Carnes e miudezas & Rússia & Japão & Arábia Saudita \\
$\begin{array}{l}\text { Preparações de carnes } \\
\text { Café e mates }\end{array}$ & Estados Unidos & Reino Unido & Paises Baixos \\
$\begin{array}{l}\text { Sementes e oleaginosas } \\
\text { Resíduos de indústrias }\end{array}$ & Alemanha & Estados Unidos & Itália \\
alimentares & China & Paises Baixos & Espanha \\
$\begin{array}{l}\text { Açúcares e confeitaria } \\
\text { Preparações de hortícolas }\end{array}$ & Rússia & França & Alemanha \\
Algodão & Bélgica & Países Baixos & Estados Unidos \\
\hline
\end{tabular}

Fonte: Elaboração própria a partir de Aliceweb (http://aliceweb.mdic.gov.br/).

Nota: Carnes: capítulos 02 e 16 (carnes e miudezas, e preparações de carnes) da Nomenclatura Comum do Mercosul (NCM); café: capítulo 09 (café e mates); soja: capítulos 12 e 23 (sementes e oleaginosas, e resíduos de indústrias alimentares); açúcar: capítulo 17 (açúcares e confeitaria); suco de laranja: capítulo 20 (preparações de hortícolas); algodão: capítulo 52 (algodão).

A título de exemplo, no caso de itens como sementes e oleaginosas, açúcares e confeitaria, e algodão, alguns dos grandes importadores 
de produtos brasileiros em 2005 foram integrantes do G20, conforme observável na Tabela 3.

Diversas especificações do modelo empírico foram utilizadas e estimadas via mínimos quadrados ordinários em dados painel (pooled OLS). Essas especificações referem-se ao conjunto dos produtos da pauta agro exportadora brasileira. O uso das várias especificações visa realizar um teste de sensibilidade dos coeficientes obtidos, como será abordado com mais detalhes a seguir.

É igualmente válido incluir as características geográficas dos países porque elas têm efeitos importantes sobre os fluxos comerciais e são, em regra, não correlacionadas com outros determinantes da renda. Em outros termos, ainda que características geográficas não sejam uma conseqüência da renda ou da política dos países, elas são fatores importantes para facilitar ou restringir fluxos e direções comerciais. Como dito anteriormente, o presente trabalho inclui variáveis dummies de localização geográfica, i.e., os continentes em que os países importadores estão localizados.

Outra necessidade é reconhecer a existência de fatores históricos, culturais, étnicos, políticos e geográficos que afetam o nível e as direções do comércio. Tais fatores podem estar correlacionados com as variáveis “de gravidade” (PIB, população, e distância). Nesse contexto, as estimativas que não contemplem tais fatores adicionais poderiam apresentar viés (CHENG e WALL, 2004). Esse condicionante levou à utilização da estratégia empírica de estimação de modelos de efeitos fixo e aleatório.

Os modelos de efeitos fixo e aleatório podem ser representados para o contexto desse trabalho na expressão abaixo:

$$
\ln F_{i j t}=\alpha_{0}+\sum_{i=1}^{n} \beta_{k} \ln X_{k i j t}+\varepsilon_{i j t}
$$

Em que:

- $\quad$ no modelo de efeito fixo $\alpha_{0}$ é variável para cada par i e j, e não varia com o tempo, mas sobretudo em função daquele específico parceiro comercial. Aqui, a variação seria somente em função de j (país importador), porque i é um exportador fixo, no caso, o Brasil;

- $\quad$ no modelo de efeito aleatório, $\alpha_{\mathrm{i}}=\alpha_{0}+\xi_{\mathrm{i}}$, sendo $\alpha_{0}$ constante 
e $\xi_{\mathrm{l}}$, um termo errático não correlacionado com as variáveis explanatórias do modelo para cada específico país importador.

No que tange ao funcionamento e à implementação dos modelos, a principal diferença entre as duas estratégias de modelagem está na matriz de variância e covariância que decorre da presença do termo errático no segundo modelo.

Em alguns casos, uma comparação inter-países pode também incluir o conjunto completo de unidades geográficas para as quais é razoável assumir que as diferenças entre unidades podem ser representadas por deslocamentos conhecidos (ou não erráticos) de $\alpha_{0}$ (efeito fixo) Em outros casos, pode ser mais apropriado raciocinar a constante de cada específico grupo cross-section como aleatoriamente distribuída (efeito aleatório) (GREENE, 2000).

Dada a natureza dos dados aqui trabalhados, esses modelos representam possibilidades adicionais bastante interessantes, uma vez que é razoável assumir que variáveis relevantes são distintas por parceria comercial (efeito fixo) e não necessariamente conhecidas de ano a ano ou mesmo não passíveis de quantificação por sua própria natureza (efeito aleatório).

Nessa linha, incluem-se barreiras sanitárias, fito-sanitárias, ou mesmo regulamentações técnicas ou de rotulagem, que por certo oscilam de país para país bem como ao longo dos anos, muitas vezes de forma arbitrada, como resultado de ações de economia política (liberalizante ou protecionista) ${ }^{11}$. Além disso, a própria existência de diferentes cronogramas e estruturas de desgravamento tarifário, regras de origem e listas de exceção comercial dentre grupos de produtos reforça tal raciocínio.

Note que a variável preço não foi incluída explicitamente. Segundo Anderson (1979), no modelo gravitacional, quase necessariamente a diferenciação relaciona-se ao local de origem (ou à distância) do produtor.

${ }^{11}$ Segundo CEPEA (2007) é possível observar que as barreiras não tarifárias assumem hoje um papel crescente em termos de restrições às movimentações comerciais. 


\section{Resultados}

Como frisado anteriormente, estimaram-se diversas especificações do modelo gravitacional. Precisamente, quatro especificações diferentes foram postuladas. Na primeira tabela de resultados, os modelos foram estimados via Pooled OLS do mais parcimonioso - em termos das variáveis explicativas - para o mais inclusivo ${ }^{12}$. Tal exercício visa testar a sensibilidade dos resultados e coeficientes estimados das variáveis inclusas no modelo gravitacional. Isto posto, adiciona-se ao modelo gravitacional clássico variáveis que potencialmente explicam a relação do fluxo comercial agropecuário brasileiro, como feito em vários estudos que incluem na especificação empírica variáveis de economia política, macroeconomia e de análise regional-espacial (SEVELA, 2002; ZAHNISER et al., 2002; POROJAN, 2000).

A primeira especificação inclui somente duas variáveis na abordagem gravitacional: Produto Interno Bruto (PIB) dos países importadores e a distância dos mesmos até o Brasil. Ambas variáveis são significativas a $1 \%$. Os resultados indicam que quanto mais distante for o país, menor sua aquisição de produtos agropecuários brasileiros. Resultado contrário é verificado para a variável PIB: quanto maior a economia do parceiro comercial, mais ele importa produtos agropecuários do Brasil.

Tal resultado permanece para as diversas especificações utilizadas, e o que muda são as magnitudes dos coeficientes. A título de ilustração, para a equação (1), o coeficiente da variável PIB total é 1,12 , enquanto que na especificação (3) é 0,76 . Para o caso do PIB do importador, caso a economia do país comprador cresça $1 \%$, haverá um aumento na importação de produtos agropecuários brasileiros de aproximadamente $0,76 \%$.

A distância dos mercados compradores é a variável que exibe maior impacto individual negativo para as vendas brasileiras de produtos agropecuários. O aumento de $1 \%$ na distância do Brasil para um de seus parceiros comerciais equivale a uma queda de aproximadamente 2,38\%

${ }^{12}$ Como checagem, tanto para o caso geral como para os maiores países, também foram estimados modelos Pooled OLS com dummies para os diferentes anos da amostra. Todavia, os parâmetros estimados e a significância estatística dessas estimativas pouco diferiram dos resultados apresentados na Tabela 4 e, portanto, não são reportadas. 
(modelo 3) nas vendas de produtos agropecuários brasileiros. Nesse sentido, as exportações agropecuárias brasileiras são negativamente elásticas à distância para com os mercados consumidores externos.

As dummies para regiões geográficas retratam uma atração positiva exercida pelos países do Leste Asiático e Pacífico, provavelmente associada à presença de Japão, China e Índia. Ao mesmo tempo, os países latino-americanos e africanos não se mostraram receptivos às exportações agropecuárias do Brasil, quase certamente por conta do baixo dinamismo econômico que se tem verificado naquelas áreas.

As exportações agropecuárias brasileiras também reagiram positivamente a incrementos na população de nossos parceiros comerciais. $\mathrm{O}$ crescimento de $1 \%$ na população dos países compradores acarreta acréscimos de divisas de exportações agropecuárias da ordem de $0,28 \%$ a 0,38\%.

Por outro lado, o fato de o país comprador elevar a participação de suas exportações agropecuárias nas exportações totais impacta negativamente as exportações agropecuárias do Brasil, embora esse impacto seja relativamente pequeno. Um ponto percentual (p.p.) a mais na participação de produtos agropecuários na pauta total de exportações do comprador externo acarreta em aproximadamente 0,02 p.p. de redução nas importações de produtos agropecuários oriundos do Brasil.

Vale ressaltar que a porcentagem da população rural na população total do país estrangeiro não se mostrou estatisticamente significante para explicar o desempenho das exportações agropecuárias brasileiras. Esse resultado pode ser compreendido à medida que, mesmo no Brasil, a população rural não está necessariamente engajada em atividades de produção agropecuária ${ }^{13}$.

Igualmente importante observar que, nas estimativas apresentadas, o crescimento da economia brasileira não mostrou efeito significativo sobre o desempenho do setor exportador agropecuário. Ao mesmo tempo, o impacto da taxa de câmbio sobre as exportações agropecuárias brasileiras mostrou-se substancialmente pequeno ou mesmo nulo. Resultados similares já haviam sido encontrados em trabalhos anteriores de outros pesquisadores, como descrito no item 2 referente à revisão da literatura.

${ }^{13}$ Para um aprofundamento do caso brasileiro, veja-se Ferreira et al. (2006). 
Tabela 4 - Resultados da estimação via Pooled OLS para o caso geral.

\begin{tabular}{|c|c|c|c|c|}
\hline$:$ & $\begin{array}{c}(1) \\
\text { Lexpagr1 }\end{array}$ & $\begin{array}{c}(2) \\
\text { Lexpagr2 }\end{array}$ & $\begin{array}{c}(3) \\
\text { Lexpagr3 }\end{array}$ & $\begin{array}{c}(4) \\
\text { Lexpagr4 }\end{array}$ \\
\hline Distância até o Brasil (ln) & $\begin{array}{c}-1.0294 * * \\
(0.1328)\end{array}$ & $\begin{array}{l}-2.5613^{* *} \\
(0.2986)\end{array}$ & $\begin{array}{l}-2.3812^{* *} \\
(0.3096)\end{array}$ & $\begin{array}{l}-2.5738^{* *} \\
(0.3039)\end{array}$ \\
\hline PIB total (ln) & $\begin{array}{l}1.1199 * * \\
(0.0296)\end{array}$ & $\begin{array}{l}0.7327^{* *} \\
(0.0966)\end{array}$ & $\begin{array}{l}0.7636^{* *} \\
(0.0973)\end{array}$ & $\begin{array}{l}0.7337^{* *} \\
(0.0968)\end{array}$ \\
\hline Dummy - África & & $\begin{array}{c}-1.0196^{* *} \\
(0.2820)\end{array}$ & $\begin{array}{c}-0.9162^{* *} \\
(0.2851)\end{array}$ & $\begin{array}{c}-1.0257^{* *} \\
(0.2836)\end{array}$ \\
\hline Dummy - Ásia & & $\begin{array}{c}0.4043 \\
(0.2959)\end{array}$ & $\begin{array}{c}0.2519 \\
(0.3036)\end{array}$ & $\begin{array}{c}0.4008 \\
(0.2967)\end{array}$ \\
\hline Dummy - América Latina & & $\begin{array}{l}-2.1687^{* *} \\
(0.3431)\end{array}$ & $\begin{array}{l}-2.2287^{* *} \\
(0.3428)\end{array}$ & $\begin{array}{l}-2.1905^{* *} \\
(0.3564)\end{array}$ \\
\hline População (ln) & & $\begin{array}{l}0.3788^{* *} \\
(0.0961)\end{array}$ & $\begin{array}{l}0.2855^{* *} \\
(0.1056)\end{array}$ & $\begin{array}{l}0.3742^{* *} \\
(0.0983)\end{array}$ \\
\hline \% do setor agrícola no PIB & & $\begin{array}{l}-0.0123 \\
(0.0112)\end{array}$ & $\begin{array}{l}-0.0125 \\
(0.0112)\end{array}$ & $\begin{array}{l}-0.0121 \\
(0.0113)\end{array}$ \\
\hline $\begin{array}{c}\% \text { das exportações agropecuárias } \\
\text { nas exportações totais }\end{array}$ & & $\begin{array}{l}-0.0214^{* *} \\
(0.0071)\end{array}$ & $\begin{array}{l}-0.0203^{* *} \\
(0.0070)\end{array}$ & $\begin{array}{l}-0.0214^{* *} \\
(0.0071)\end{array}$ \\
\hline $\begin{array}{l}\text { \% da população rural } \\
\text { na população total }\end{array}$ & & $\begin{array}{l}-0.0041 \\
(0.0063)\end{array}$ & $\begin{array}{l}-0.0050 \\
(0.0063)\end{array}$ & $\begin{array}{l}-0.0042 \\
(0.0064)\end{array}$ \\
\hline Taxa de câmbio & & $\begin{array}{c}0.0002 \\
(0.0001)\end{array}$ & $\begin{array}{l}0.0002 * \\
(0.0001)\end{array}$ & $\begin{array}{c}0.0002 \\
(0.0001)\end{array}$ \\
\hline PIB per capita do Brasil & & $\begin{array}{c}0.2252 \\
(0.3503)\end{array}$ & $\begin{array}{c}0.2484 \\
(0.3490)\end{array}$ & $\begin{array}{c}0.2286 \\
(0.3511)\end{array}$ \\
\hline G20 & & & $\begin{array}{l}0.5259 * \\
(0.2524)\end{array}$ & \\
\hline Dymmy - China e Índia & & & & $\begin{array}{c}0.1074 \\
(0.4687)\end{array}$ \\
\hline Constante & $\begin{array}{l}-1.3130 \\
(1.1540)\end{array}$ & $\begin{array}{c}14.8341^{* *} \\
(4.2211)\end{array}$ & $\begin{array}{l}13.7359 * * \\
(4.2357)\end{array}$ & $\begin{array}{l}14.9716^{* *} \\
(4.2688)\end{array}$ \\
\hline Número de Observações & 709 & 394 & 394 & 394 \\
\hline R-quadrado ajustado & 0.67 & 0.73 & 0.73 & 0.73 \\
\hline
\end{tabular}

Fonte: elaboração própria.

Notas: $1 .{ }^{*}$ significância a $5 \% ;{ }^{* *}$ significância a $1 \%$. 2. desvio-padrão entre parênteses. 
Entretanto, como discutido na seção metodológica, resultados mais acurados podem ser obtidos com a implementação dos procedimentos de efeito fixo ou aleatório na equação gravitacional. Isto feito, os respectivos resultados são apresentados à frente.

As estatísticas usuais foram empregadas para averiguar o uso dos modelos de efeito fixo/aleatório. A estatística do teste de BreuschPagan para os modelos estimados foi significativa. O teste de Breusch-Pagan é utilizado para mensurar a estrutura de variância dos resíduos da regressão clássica por mínimos quadrados, e se aplica para avaliação de homocedasticidade dos mesmos, sendo considerado um teste assintótico com distribuição de $\chi^{2}$. No caso do presente estudo, as fontes amostradas representam a própria população objeto de análise nos anos avaliados ${ }^{14}$.

Desta forma, para o nível de significância de $1 \%$ rejeitou-se a hipótese de que o modelo de pooled mínimos quadrados ordinários (Pooled OLS) era apropriado, significando que o modelo correto poderia ser o de efeitos fixos ou aleatórios. A estatística do teste de Hausman para os modelos estimados foi não significativa a $5 \%$, demonstrando que o método de estimação de efeitos aleatórios é o que melhor se ajusta aos dados.

O modelo de efeitos aleatórios aparenta ser mais apropriado para captar variáveis não-explícitas e de incidência errática. A título de ilustração, podem-se citar mudanças de governo nos países importadores, mudanças de classificação do Brasil nos acordo preferenciais de comércio e mesmo crises cambiais locais (i.e., dos mercados de destino).

A Tabela 5 exibe as quatro especificações para o procedimento de efeitos aleatórios implementado. Em termos de significância dos parâmetros, os resultados variaram pouco entre as diversas especificações. Similarmente, aqui as exportações agropecuárias brasileiras são negativamente elásticas à distância para os mercados de destino: um incremento de $1 \%$ na distância do Brasil para um de seus parceiros comerciais gera, na média, um recuo de cerca de $2,50 \%$ nas vendas desses produtos.

De outra parte, agora o impacto do PIB externo sobre as exportações agropecuárias brasileiras é maior, ou seja, um acréscimo de 0,92\% (contra $0,76 \%$ nas estimativas Pooled OLS, Tabela 4) nas vendas desses produtos a cada $1 \%$ de crescimento do PIB do país importador.

${ }^{14}$ Detalhamentos sobre o teste podem ser encontrados em Koenker (1981). 
Tabela 5 - Resultados da estimação via RE (random effects) para o caso geral.

\begin{tabular}{|c|c|c|c|c|}
\hline & $\begin{array}{c}(1) \\
\text { Lexpagr1 }\end{array}$ & $\begin{array}{c}(2) \\
\text { Lexpagr2 }\end{array}$ & $\begin{array}{c}(3) \\
\text { Lexpagr3 }\end{array}$ & $\begin{array}{c}(4) \\
\text { Lexpagr4 }\end{array}$ \\
\hline Distância até o Brasil (ln) & $\begin{array}{c}-1.2264^{* *} \\
(0.2973)\end{array}$ & $\begin{array}{c}-2.5593 * * \\
(0.5939)\end{array}$ & $\begin{array}{c}-2.4528^{* *} \\
(0.6234)\end{array}$ & $\begin{array}{c}-2.5749 * * \\
(0.6059)\end{array}$ \\
\hline PIB total $(\ln )$ & $\begin{array}{c}1.1684^{* *} \\
(0.0648)\end{array}$ & $\begin{array}{c}0.9153^{* *} \\
(0.1784)\end{array}$ & $\begin{array}{c}0.9297 * * \\
(0.1804)\end{array}$ & $\begin{array}{c}0.9180 * * \\
(0.1795)\end{array}$ \\
\hline Dummy - África & & $\begin{array}{c}-0.9163 \\
(0.5428)\end{array}$ & $\begin{array}{l}-0.8644 \\
(0.5521)\end{array}$ & $\begin{array}{l}-0.9255 \\
(0.5500)\end{array}$ \\
\hline Dummy - Ásia & & $\begin{array}{c}0.2879 \\
(0.5480)\end{array}$ & $\begin{array}{c}0.1953 \\
(0.5722)\end{array}$ & $\begin{array}{c}0.2827 \\
(0.5528)\end{array}$ \\
\hline Dummy - América Latina & & $\begin{array}{c}-2.0268 * * \\
(0.6700)\end{array}$ & $\begin{array}{c}-2.0525^{* *} \\
(0.6741)\end{array}$ & $\begin{array}{c}-2.0518^{* *} \\
(0.6958)\end{array}$ \\
\hline População (ln) & & $\begin{array}{c}0.2295 \\
(0.1770)\end{array}$ & $\begin{array}{c}0.1821 \\
(0.1942)\end{array}$ & $\begin{array}{c}0.2232 \\
(0.1805)\end{array}$ \\
\hline \% do setor agrícola no PIB & & $\begin{array}{c}0.0083 \\
(0.0187)\end{array}$ & $\begin{array}{c}0.0085 \\
(0.0188)\end{array}$ & $\begin{array}{c}0.0089 \\
(0.0189)\end{array}$ \\
\hline $\begin{array}{c}\% \text { das exportações agropecuárias } \\
\text { nas exportações totais }\end{array}$ & & $\begin{array}{c}-0.0263^{*} \\
(0.0110)\end{array}$ & $\begin{array}{c}-0.0256^{*} \\
(0.0111)\end{array}$ & $\begin{array}{c}-0.0264 * \\
(0.0111)\end{array}$ \\
\hline \% da população rural na população total & & $\begin{array}{l}-0.0007 \\
(0.0116)\end{array}$ & $\begin{array}{l}-0.0011 \\
(0.0116)\end{array}$ & $\begin{array}{l}-0.0007 \\
(0.0116)\end{array}$ \\
\hline Taxa de câmbio & & $\begin{array}{c}0.0001 \\
(0.0001)\end{array}$ & $\begin{array}{c}0.0001 \\
(0.0001)\end{array}$ & $\begin{array}{c}0.0001 \\
(0.0001)\end{array}$ \\
\hline PIB per capita do Brasil & & $\begin{array}{c}0.1540 \\
(0.2304)\end{array}$ & $\begin{array}{c}0.1549 \\
(0.2305)\end{array}$ & $\begin{array}{c}0.1534 \\
(0.2305)\end{array}$ \\
\hline G20 & & & $\begin{array}{c}0.2943 \\
(0.4989)\end{array}$ & \\
\hline Dymmy - China e Índia & & & & $\begin{array}{c}0.1463 \\
(0.9972)\end{array}$ \\
\hline Constante & $\begin{array}{c}-0.7974 \\
(2.6550)\end{array}$ & $\begin{array}{c}12.9676^{*} \\
(6.2521)\end{array}$ & $\begin{array}{l}12.3885 \\
(6.3498) \\
\end{array}$ & $\begin{array}{c}13.1457^{*} \\
(6.4198)\end{array}$ \\
\hline Número de Observações & 709 & 394 & 394 & 394 \\
\hline Breusch-Pagan & 808.34 & 260.90 & 250.52 & 260.66 \\
\hline $\mathrm{p}$-value & 0.0000 & 0.0000 & 0.0000 & 0.0000 \\
\hline Hausman & 0.01 & 11.46 & 11.57 & 11.40 \\
\hline p-value & 0.9149 & 0.0753 & 0.0722 & 0.0767 \\
\hline
\end{tabular}

Fonte: elaboração própria.

Notas: $1 .{ }^{*}$ significância a $5 \% ;{ }^{*}$ significância a $1 \% .2$ desvio-padrão entre parênteses. 
Novamente, as exportações agropecuárias brasileiras mostraram reação negativa ao crescimento da pauta agropecuária nas exportações totais do país comprador e também negativamente afetadas pela localização geográfica na América Latina.

Por fim, foram calculados valores para aferição de robustez dos resultados, consoante as Tabelas 6 e 7 . Nesse contexto, foram estimados modelos com cortes por tamanho (de população) dos mercados de destino dos produtos sob análise. Os modelos empíricos são semelhantes em termos de variáveis empregadas aos (3) e (4) das Tabelas 4 e 5.

O primeiro corte levou em conta somente os países com 5 milhões de habitantes ou mais, o que excluiu um grande número de ilhas independentes e países de pequenas dimensões geográficas e econômicas. Já o segundo corte selecionou apenas os países com pelo menos 25 milhões de habitantes.

O primeiro corte (Tabela 6) implementado com o procedimento de efeito aleatório repetiu o sinal dos resultados da Tabela 5 para as variáveis distância, PIB do mercado de destino, e localização na América Latina, registrando-se flutuação nos valores dos parâmetros. Não obstante, deve-se observar que as variáveis proporção do setor agrícola no PIB (país de destino), taxa de câmbio e PIB per capita do Brasil tornaram-se significativas estatisticamente a $1 \%$ e com os sinais esperados em teoria.

Na transição para o segundo corte, em países de pelo menos 25 milhões de habitantes, o mesmo procedimento diagnosticou um menor número de variáveis explanatórias significativas ${ }^{15}$, comparativamente ao corte anterior. Nesse caso, nenhuma dummy para região geográfica foi significativa.

Ademais, as variáveis distância, PIB do parceiro comercial, e taxa de câmbio continuaram significativas estatisticamente, mas com respostas menores sobre as exportações agropecuárias brasileiras. Para esse segundo critério, comparativamente ao anterior, apenas a variável porcentagem do setor agrícola no PIB do país destino mostrou maior nível de impacto sobre as exportações analisadas (especificação 4).

${ }^{15}$ Sempre se referindo ao período para o qual os dados estiveram disponíveis. 
Tabela 6 - Teste de robustez para países com mais de 5 milhões de habitantes.

\begin{tabular}{|c|c|c|c|c|}
\hline \multirow[b]{3}{*}{ Variável Dependente: Inexpagr } & \multicolumn{4}{|c|}{ Acima de 5 milhões de habitantes } \\
\hline & (1) & (2) & (3) & (4) \\
\hline & OLS & OLS & RE & RE \\
\hline \multirow[t]{2}{*}{ Distância até o Brasil (ln) } & $-2.2444 * *$ & $-2.6217^{* *}$ & $-2.2145^{* *}$ & $-2.5668 * *$ \\
\hline & $(0.3455)$ & $(0.3422)$ & $(0.7827)$ & $(0.7541)$ \\
\hline \multirow[t]{2}{*}{ PIB total (ln) } & $0.8674^{* *}$ & $0.8578^{* *}$ & $0.9887^{* *}$ & $0.9636^{* *}$ \\
\hline & $(0.1189)$ & $(0.1210)$ & $(0.2294)$ & $(0.2298)$ \\
\hline Dummy - África & $\begin{array}{c}0.3609 \\
(0.3948)\end{array}$ & $\begin{array}{c}0.2855 \\
(0.4007)\end{array}$ & $\begin{array}{c}0.1914 \\
(0.2327)\end{array}$ & $\begin{array}{c}0.1802 \\
(0.2325)\end{array}$ \\
\hline \multirow[t]{2}{*}{ Dummy - Ásia } & $0.0002^{*}$ & 0.0002 & 0.0002 & 0.0002 \\
\hline & $(0.0001)$ & $(0.0001)$ & $(0.0001)$ & $(0.0001)$ \\
\hline \multirow[t]{2}{*}{ Dummy - América Latina } & $-1.4136^{* *}$ & $-1.8754^{* *}$ & $-2.0259^{*}$ & $-2.3210^{* *}$ \\
\hline & $(0.4082)$ & $(0.4046)$ & $(0.8172)$ & $(0.8043)$ \\
\hline \multirow[t]{2}{*}{ População (ln) } & 0.0085 & 0.2529 & 0.0979 & 0.2935 \\
\hline & $(0.3166)$ & $(0.3120)$ & $(0.7297)$ & $(0.7087)$ \\
\hline \multirow[t]{2}{*}{$\%$ do setor agrícola no PIB } & $-2.9882 * *$ & $-2.9021 * *$ & $-2.8615^{* *}$ & $-2.9298 * *$ \\
\hline & $(0.4017)$ & $(0.4242)$ & $(0.8927)$ & $(0.9300)$ \\
\hline \multirow{2}{*}{$\begin{array}{c}\text { \% das exportações agropecuárias } \\
\text { nas exportações totais }\end{array}$} & 0.1986 & $0.3038^{*}$ & 0.0181 & 0.0967 \\
\hline & $(0.1411)$ & $(0.1421)$ & $(0.3020)$ & $(0.2832)$ \\
\hline \multirow{2}{*}{$\begin{array}{c}\% \text { da população rural na população } \\
\text { total }\end{array}$} & $-0.0255^{* *}$ & $-0.0229 * *$ & -0.0294 & -0.0276 \\
\hline & $(0.0085)$ & $(0.0086)$ & $(0.0175)$ & $(0.0175)$ \\
\hline \multirow[t]{2}{*}{ Taxa de câmbio } & $0.0476^{*}$ & $0.0597 * *$ & $0.0951^{* *}$ & $0.0983^{* *}$ \\
\hline & $(0.0192)$ & (0.0199) & $(0.0249)$ & $(0.0252)$ \\
\hline \multirow[t]{2}{*}{ PIB per capita do Brasil } & $-0.0238^{* *}$ & $-0.0262 * *$ & $-0.0329 * *$ & $-0.0344 * *$ \\
\hline & $(0.0074)$ & $(0.0076)$ & $(0.0122)$ & $(0.0124)$ \\
\hline \multirow[t]{2}{*}{ G20 } & $0.8734^{* *}$ & & 0.6165 & \\
\hline & $(0.2770)$ & & $(0.6120)$ & \\
\hline \multirow[t]{2}{*}{ Dummy - China e Índia } & & 0.5086 & & 0.8262 \\
\hline & & $(0.4873)$ & & $(1.1287)$ \\
\hline \multirow[t]{2}{*}{ Constante } & $10.5881^{*}$ & $13.0421^{* *}$ & 11.4714 & 14.0748 \\
\hline & $(4.6733)$ & $(4.8270)$ & $(7.7281)$ & $(8.0728)$ \\
\hline Número de Observações & 277 & 277 & 277 & 277 \\
\hline R-quadrado ajustado & 0.70 & 0.69 & & \\
\hline Breusch-Pagan & & & 207.42 & 224.59 \\
\hline p-value & & & 0.0000 & 0.0000 \\
\hline Hausman & & & 8.38 & 7.61 \\
\hline p-value & & & 0,2118 & 0,2681 \\
\hline
\end{tabular}

Fonte: elaboração própria.

Notas: $1 .{ }^{*}$ significância a $5 \%$; ** significância a $1 \%$. 2. desvio-padrão entre parênteses. 
Tabela 7 - Teste de robustez para países com mais de 25 milhões de habitantes.

\begin{tabular}{|c|c|c|c|c|}
\hline \multirow[b]{3}{*}{ Variável Dependente: Inexpagr } & \multicolumn{4}{|c|}{ Acima de 25 milhões de habitantes } \\
\hline & (1) & $(2)$ & (3) & (4) \\
\hline & OLS & OLS & RE & RE \\
\hline \multirow[t]{2}{*}{ Distância até o Brasil (ln) } & $-2.1328^{* *}$ & $-2.2904^{* *}$ & -1.9378 & $-2.4939 *$ \\
\hline & $(0.4005)$ & $(0.4151)$ & $(1.1498)$ & $(1.1312)$ \\
\hline \multirow[t]{2}{*}{ PIB total (ln) } & $0.3627^{*}$ & $0.3397^{*}$ & $0.7713^{*}$ & $0.6995^{*}$ \\
\hline & $(0.1485)$ & $(0.1505)$ & $(0.3563)$ & $(0.3467)$ \\
\hline \multirow[t]{2}{*}{ Dummy - África } & 0.3280 & 0.3088 & 0.1296 & 0.1098 \\
\hline & $(0.4196)$ & $(0.4251)$ & $(0.2422)$ & $(0.2422)$ \\
\hline \multirow[t]{2}{*}{ Dummy - Ásia } & -0.0005 & -0.0006 & 0.0004 & 0.0004 \\
\hline & $(0.0004)$ & $(0.0004)$ & $(0.0006)$ & $(0.0006)$ \\
\hline \multirow[t]{2}{*}{ Dummy - América Latina } & -0.6637 & -0.8388 & -1.3909 & -1.7295 \\
\hline & $(0.4203)$ & $(0.4444)$ & $(1.0439)$ & $(1.0466)$ \\
\hline \multirow[t]{2}{*}{ População (ln) } & 0.0363 & 0.2477 & -0.2167 & 0.0812 \\
\hline & $(0.3444)$ & $(0.3247)$ & $(0.9203)$ & $(0.8452)$ \\
\hline \multirow[t]{2}{*}{$\%$ do setor agrícola no PIB } & $-2.8202 * *$ & $-2.7196^{* *}$ & $-2.7185^{*}$ & $-3.2623^{*}$ \\
\hline & $(0.4765)$ & $(0.5699)$ & $(1.2845)$ & $(1.4168)$ \\
\hline \multirow{2}{*}{$\begin{array}{c}\text { \% das exportações agropecuárias nas } \\
\text { exportações totais }\end{array}$} & $0.6732 * *$ & $0.7325^{* *}$ & 0.0844 & 0.1289 \\
\hline & $(0.2117)$ & $(0.2257)$ & $(0.5240)$ & $(0.4922)$ \\
\hline \multirow{2}{*}{$\begin{array}{l}\text { \% da população rural na população } \\
\text { total }\end{array}$} & $-0.0253^{*}$ & -0.0245 & -0.0233 & -0.0229 \\
\hline & $(0.0123)$ & $(0.0128)$ & $(0.0311)$ & $(0.0309)$ \\
\hline \multirow[t]{2}{*}{ Taxa de câmbio } & 0.0042 & 0.0139 & $0.0730^{*}$ & $0.0783^{*}$ \\
\hline & $(0.0225)$ & $(0.0247)$ & $(0.0313)$ & $(0.0317)$ \\
\hline \multirow[t]{2}{*}{ PIB per capita do Brasil } & -0.0342 & -0.0506 & -0.0305 & -0.0349 \\
\hline & $(0.0370)$ & $(0.0361)$ & $(0.0567)$ & $(0.0558)$ \\
\hline G20 & $\begin{array}{c}0.4488 \\
(0.2642)\end{array}$ & & $\begin{array}{c}0.5970 \\
(0.6931)\end{array}$ & \\
\hline Dymmy - China e Índia & & 0.1370 & & 1.2456 \\
\hline & & $(0.4659)$ & & $(1.1228)$ \\
\hline Constante & $\begin{array}{c}15.1212^{* *} \\
(5.4161)\end{array}$ & $\begin{array}{c}16.2679 * * \\
(5.9082)\end{array}$ & $\begin{array}{c}13.9347 \\
(10.8348)\end{array}$ & $\begin{array}{c}20.3607 \\
(11.8363)\end{array}$ \\
\hline Número de Observações & 117 & 117 & 117 & 117 \\
\hline R-quadrado ajustado & 0.65 & 0.65 & & \\
\hline Breusch-Pagan & & & 67,52 & 74,24 \\
\hline p-value & & & 0.0000 & 0.0000 \\
\hline Hausman & & & 9,77 & 9,26 \\
\hline p-value & & & 0,2017 & 0,2346 \\
\hline
\end{tabular}

Fonte: elaboração própria.

Notas: $1 .{ }^{*}$ significância a $5 \%$; ${ }^{*}$ significância a $1 \%$. 2. desvio-padrão entre parênteses. 
Isso sinaliza uma clara diferenciação das variáveis relevantes para explicar as exportações agropecuárias brasileiras em função de características específicas de países ou grupamentos de mercados de destino desses produtos.

Adicionalmente é preciso ressaltar que, de fato, os países do G20, China e Índia não se apresentaram como fatores de atração per si. No caso do conjunto de países do G20, a não significância dos parâmetros estimados alinha-se com o fato de que esses países possuem interesses comerciais próximos aos do Brasil e, assim, é razoável que não sejam mercados naturais de atração desses itens quando produzidos na economia brasileira.

Em relação à China e à Índia, deve ser compreendido que há também dois condicionantes envolvidos. Em primeiro plano, o intervalo de dados disponível para a pesquisa (1996-2001) não atinge o período auge de grandes volumes de exportações agropecuárias brasileiras para aqueles mercados. Além disso, embora China e Índia sejam grandes mercados consumidores de alimentos e de alimentos processados, esses dois países são também grandes produtores desses bens.

\section{Considerações finais}

O presente trabalho teve por objetivo averiguar os fatores de atração das exportações agropecuárias do Brasil. Nesse contexto, propôs-se a responder a três questões específicas, ou seja, detectar as características dos parceiros comerciais que afetam as exportações desses produtos, aferir o impacto do crescimento doméstico sobre essas exportações e avaliar o efeito do perfil agroexportador dos países parceiros nas exportações agropecuárias brasileiras.

A metodologia utilizada - o modelo gravitacional - atendeu aos objetivos desenhados e sua aplicação para os propósitos empíricos estabelecidos no presente trabalho havia sido discutida recentemente em Evennet e Keller (2002) e, também, nos artigos seminais de Anderson (1979), Bergstrand (1985), e Bergstrand (1989). 
Com relação ao primeiro questionamento, as variáveis distância para o mercado de destino e Produto Interno Bruto (PIB) dos parceiros comerciais mostraram-se relevantes para o maior ou menor montante de exportações agropecuárias brasileiras no período analisado. Nesse sentido, observa-se que os países com maiores contingentes populacionais e com maior nível de atividade econômica, em termos de PIB, são os que importam mais produtos do setor agropecuário brasileiro.

Ao mesmo tempo, a desvalorização da moeda local exibiu um impacto positivo sobre as vendas agropecuárias ao exterior, quando observados os grupamentos de países por cortes populacionais no procedimento econométrico de efeitos aleatórios.

Ademais, nas estimativas referentes à implementação dos cortes por faixa populacional, identificou-se um grande efeito negativo sobre essas exportações em decorrência de aumentos da importância do setor agrícola no PIB do mercado de destino. O que seria um sinalizador de crescimento de autonomia daquele país destino no que se reporta à sua auto-suficiência na produção de alimentos.

Dentre os modelos empregados, não se identificou claro fator de atração associado à localização geográfica (África, Ásia, ou América Latina). Antes disso, no caso dos países latino-americanos, o local de identificação do país traduz-se numa menor atração dos produtos agropecuários ofertados pelo Brasil no mercado internacional. Esse resultado está provavelmente associado a estruturas produtivas substitutas nesses bens (caso da Argentina em carnes, cereais e leguminosas, por exemplo) ou mesmo por hábitos alimentares distintos (como no caso de México, com maior aceitação de milho e alimentos condimentados ou Chile e Peru, com maior preferência por peixes e bebidas).

Quanto ao segundo questionamento, o crescimento da economia local mostrou-se elemento limitante das exportações agropecuárias brasileiras somente nas estimativas do corte de países com mais de cinco milhões de habitantes. A aparente indiferença das exportações agropecuárias ao crescimento do PIB local pode estar relacionada à maior capacidade de resposta e maior habilidade de deslocamento de produção que o agronegócio brasileiro tem desenvolvido seja em 
função de maciços investimentos pregressos em tecnologia e manejo da produção (maior capacidade de resposta) seja pelo estabelecimento de cadeias de integração verticais e melhor conexão entre distribuidoras de insumo, produtores in loco, e processadores finais (deslocamento da produção). Além disso, há que se ter em mente que o período de avaliação (1996-2001) exibiu taxas de crescimento doméstico realmente bastante modestas, em patamares tais que de fato fossem pouco impactantes das vendas de bens agropecuários no mercado internacional.

Sobre esse resultado, Carvalho e De Negri (2000) haviam obtido números similares em relação à influência do PIB doméstico sobre as exportações agropecuárias. Todavia, a abertura por grupos de produtos pode revelar um caráter importante para as exportações agropecuárias, como identificado nos trabalhos de Sevela (2000) (para o caso da República Tcheca), Reis e Crespo (1998), Barros, Bacchi e Burnquist (2002) e Maia (2003), sobretudo porque os grupos de produtos agropecuários são razoavelmente distintos entre si em termos de suas estruturas de mercado, tanto no Brasil como no exterior.

Já quanto ao perfil agroexportador dos parceiros comerciais, o caso geral nos procedimentos padrão (pooled OLS) e de efeitos aleatórios identificaram um modesto impacto negativo da maior presença da pauta agroexportadora desses países sobre as exportações agropecuárias brasileiras. Como enunciado à introdução do estudo, países que são grandes produtores e vendedores de produto agropecuário (China, Índia, Rússia, Austrália e mesmo Estados Unidos e União Européia) são, igualmente, grandes importadores líquidos de inúmeros produtos que não por acaso encabeçam a lista de produtos efetivamente exportados pelo Brasil, como açúcar e carnes, para citar dois exemplos característicos.

Por fim, como visto, tanto na revisão teórica como pelos resultados diferenciados dos modelos de efeitos aleatórios (caso geral, e cortes), há relações comerciais específicas do Brasil com os demais países. Isso sugere uma diferenciação das variáveis relevantes para explicar as exportações agropecuárias brasileiras em função de características específicas de países ou grupamentos de mercados de destino desses produtos. 


\section{Referências bibliográficas}

ANDERSON, J. A. A theoretical foundation for the gravity equation. American Economic Review. v.69, n.1, p.106-116, 1979.

ANDERSON, K.; MARTIN, W.; VAN DER MENSBRUGGHE, D., Doha Merchandise Trade Reform and Developing Countries: What is at Stake? Washington. World Bank, 2005

BARROS, G. S. C.; BACCHI, M. R. P.; BURNQUIST, H. L. Estimação de equações de Oferta de Exportação de Produtos Agropecuários para o Brasil (1992/2000). Brasília: IPEA, 2002. 53p. (Texto para Discussão, 875).

BERGSTRAND, J. H.. The gravity equation in international trade: some microeconomic foundations and empirical evidence. Review of Economics and Statistics, n.67, v.3 p.474-481, 1985.

BERGSTRAND, J. H.. The generalized gravity equation monopolistic competition, and the factor proportions theory in international trade. Review of Economics and Statistics, n.71, p.143-153, 1989.

BOUËT, A. A bilateral and disaggregated measurement of agricultural market access in the European Union and in Mercosur. Paris. Centre d'Analyse Économique et de Traitement dês données économiques (CATT) / Centre d'Études Prospectives et d’Informations Internationales (CEPII), 2003. 31p.

BRAUN, M.; HAUSMANN, R.; PRITCHETT, L. Disintegration and the proliferation of sovereigns: Are there lessons for integration? Harvard University: Center for International Development (CID), 2002. 45p.

CARVALHO, A.; DE NEGRI, J. A. Estimação de equações de importação e exportação de Produtos Agropecuários para o Brasil (1977/1998). Brasília: IPEA, 2000. 30p. (Texto para Discussão, 698).

CASTILHO, M.R. O sistema de preferências comerciais da União Européia. Brasília: IPEA, 2000. 67p. (Texto para Discussão, 742) 
CASTILHO, M. R. (2001). O Acesso das exportações do Mercosul ao mercado europeu. IN: XXIX ENCONTRO NACIONAL DE ECONOMIA, Salvador, Anais, ... Salvador: ANPEC, 2001. 21p.

CENTRO DE ESTUDOS AVANÇADOS EM ECONOMIA APLICADA (CEPEA). TBT - Barreiras Técnicas ao Comércio Internacional. Piracicaba: CEPEA, 2007. 13p.

CHENG, I.H.; WALL, H.J. Controlling for heterogeneity in Gravity Models of Trade. Working Paper 99-010A. Saint Louis: Federal Reserve Bank of Saint Louis, 2004

CUNHA FILHO, J.H. As quotas tarifárias e o acesso dos produtos agroindustriais Brasileiros ao mercado internacional. 2004. 159p. Dissertação (M.S.) - Escola Superior de Agricultura “Luiz de Queiroz”, Universidade de São Paulo, Piracicaba, 2004.

DEARDOFF, A. V. Determinants of bilateral trade: does gravity work in a neoclassical world? In: The Regionalization of the World Economy (Ed. JEFFREY A. FRANKEL). Chicago: Chicago University Press, 1998. EVENETT, S. J.; KELLER, W. On Theories Explaining the Success of the Gravity Equation. Journal of Political Economy, v.110, n.2, p.281-316, 2002.

FEENSTRA, R. C.; MARKUSEN, J. R.; ROSE, A. K. Understanding the home market effect and the gravity equation: the role of differentiating goods. NBER Working Paper 6804, 1998.

FEENSTRA, R. C.; MARKUSEN, J. R.; ROSE, A. K. Using the gravity equation to differentiate among alternative theories of trade. The Canadian Journal of Economics, v.34, n.2, p.430-477, 2001.

FERREIRA, B.; BALSADI, O. V.; FREITAS, R. E..; ALMEIDA, A. N. Ocupações agrícolas e não agrícolas: trajetória e rendimentos no meio rural brasileiro. In: DE NEGRI, J.; DE NEGRI, F.; COELHO, D. (Orgs.) Tecnologia, exportação e emprego. Brasília: IPEA, 2006, v.1, p.445-488. 
FONSECA, M. B.; HIDALGO, A. B., A formação da ALCA e os prováveis efeitos sobre as exportações agrícolas brasileiras, Revista de Economia e Sociologia Rural, v. 44, n.1, pp. 9-26, 2006.

FOREIGN TRADE AND INFORMATION SERVICE (FTIS). Agreement establishing the World Trade Organization: the Uruguay round final act. Disponível em: < http://www.sice.oas.org/trade/ ur_round/URTOC. asp > . Acesso em 12 dez.. 2002.

GREENE, W. Econometric Analysis. New Jersey: Prentice-Hall, 2000. 1004p.

GUILHOTO, J. J. M.; SILVEIRA, F. G.; AZZONI, C. PIB das cadeias produtivas da agricultura familiar. Brasília: NEAD/MDA/FIPE, 2004. 32p (apresentação).

HIDALGO, A. B.; VERGOLINO, J. R. O nordeste e o comércio interregional e internacional: um teste dos impactos por meio do modelo gravitacional. Economia Aplicada, v. 2, n. 4, p. 707-725, 1998.

HOMEM DE MELO, F. B. A abertura comercial e o papel dos aumentos de produtividade na agricultura brasileira. Mimeo (s.d.). Disponível em: < http://www.ifb.com.br/documentos/hdemelo.pdf. > Acesso em 07 jul. 2005.

INSTITUTO DE ESTUDOS DO COMÉRCIO E NEGOCIAÇÕES INTERNACIONAIS (ICONE). Sobre Comércio e Negociações. Disponível no site: $<$ http://www.iconebrasil.org.br >, Acesso em 08 jan. 2007

KOENKER, R. A Note on Studentizing a test for Heterocedasticity. Journal of Econometrics, v.17, p.1180-1200, 1981.

KRUGMAN, P. Scale economies, product differentiation, and the pattern of trade. The American Economic Review, v.70, n.5, p.950-959, 1980. 
MAIA, A. G.; DEDECCA, C. S.; VIEIRA FILHO, J. E.; SILVEIRA, J. M. F. J. A evolução recente da ocupação e do rendimento no setor agrícola. IN: XLIII CONGRESSO DA SOBER, Ribeirão Preto, Anais ..., Ribeirão Preto: SOBER, 2005. 19p.

MAIA, S. F. Determinantes das exportações agrícolas em cenário de macroeconomia aberta: abordagem por modelos de séries de tempo. IN: ANAIS DO XXXI ENCONTRO NACIONAL DE ECONOMIA, Porto Seguro, Anais ..., Porto Seguro: ANPEC, 2003, 20p.

MINISTÉRIO DO DESENVOLVIMENTO INDÚSTRIA E COMÉRCIO EXTERIOR (MDIC). Barreiras externas às exportações brasileiras 2001. Brasília: MCID, 2001. 86p.

MINISTÉRIO DO DESENVOLVIMENTO INDÚSTRIA E COMÉRCIO EXTERIOR (MDIC). Aliceweb. Brasília: MCID. Disponível em: < http:// aliceweb.mdic.gov.br/ >. Acesso: 13 fev. 2007.

PAZ, L. S.; FRANCO NETO, A., A Brazilian border and MERCOSUR integration effects: an exploratory assessment using the gravity model. IN: ANAIS DO XXXI ENCONTRO NACIONAL DE ECONOMIA, Porto Seguro, Anais ..., Porto Seguro: ANPEC, 2003, 21p.

PIANI, G.; KUME, H. Fluxos bilaterais de comércio e blocos regionais: uma aplicação do modelo gravitacional. Rio de Janeiro: Ipea, jul. 2000. 22p. (Texto para Discussão, n. 749).

POROJAN, A., Trade Flows and Spatial Effects: the Gravity Model Revisited. Derby: Universtity of Derby, 2000. 15p.

REIS, J. N. P.; CRESPO, J. E. Q., Um Modelo Econométrico para as Exportações de Açúcar do Brasil. Agricultura em São Paulo, São Paulo, v.45, n.1, p.17-32, 1998.

SEVELA, M., Gravity type-model of Czech agricultural export. Agricultural Economics, v, 48, p.463-466, 2002. 
SANTOS SILVA, J.; TENREYRO, S. 2005. The Log of Gravity. CEPR Discussion Paper no. 5.311. London: Centre for Economic Policy Research. Disponível em: < http://www.cepr.org/pubs/dps/DP5311.asp $>$. Acesso 15 mai. 2006.

UNITED NATIONS (UN). Growth in United Nations Membership, 19452005. Disponível em: < http://www.un.org/Overview/growth.htm. > Acesso: 22 mar. 2005.

WORLD TRADE ORGANIZATION (WTO). Regional Trade Agreements: facts and figures. Bruxelas: World Trade Organization, Disponível em: < http://www.wto.org/english/tratop_e/region_e/regfac_e.htm > Acesso: 22 mar. 2005.

ZAHNISER, S.; PICK, D.; POMPELLI; G. M.; GEHLHAR, M. J. Regionalism in the western hemisphere and its impact on U.S. agricultural exports: a gravity-model analysis. American Journal of Agricultural Economics, v.84, n.3, p.791-797, 2002. 